\title{
Mineraçãào
}

\section{Simulação de moagem mista por rede neural artificial}

\author{
Mix grinding simulation by \\ artificial neural network
}

\author{
Germano Mendes Rosa \\ Instituto Federal Minas Gerais - IFMG \\ Campus Congonhas \\ Coordenadoria de Engenharia de \\ Produção e Mineração \\ Mestre pelo PPGEM/UFOP \\ germano.rosa@ifmg.edu.br \\ José Aurélio Medeiros da Luz \\ Universidade Federal de Ouro Preto - UFOP \\ Escola de Minas \\ Departamento de Engenharia de Minas - DEMIN. \\ jaurelio@demin.ufop.br
}

\section{Resumo}

Esse artigo versa sobre a aplicação de um simulador de moagem mista baseado em redes neurais artificiais (do tipo perceptron multicamadas com treinamento supervisionado com o algoritmo retropropagação com momento). Os dados experimentais aqui utilizados provieram do trabalho atinente ao artigo intitulado "Seletividade na cominuição de mesclas de dolomita e quartzo". Para verificar a estabilidade estatística do processo de simulação, utilizou-se a carta de controle Shewhart para valores individuais, a qual se mostrou útil para orientar a aceitação dos treinamentos. Os resultados mostraram bom desempenho dessa ferramenta na simulação de moagem mista (moagem de mistura de componentes de diferentes moabilidades), problema de comum ocorrência no setor minerometalúrgico.

Palavras-chave: Cominuição seletiva, distribuição granulométrica, rede neural artificial, simulação, carta de controle.

\begin{abstract}
This paper discusses the results of a mixed grinding simulator application based on an artificial neural network (multiple-layer perceptron using a back-propagationlike algorithm with moment). The data used came from a previous paper entitled "Selective grinding of dolomite and quartz mixes". The Shewhart control chart for individual values was used in order to verify the statistical stability of the simulation process results, which was useful for testing acceptance. The results have displayed good performance of this tool related to mix grinding simulation, a common issue in the mining and metallurgical sectors.
\end{abstract}

Keywords: Selective grinding, size distribution, artificial neural network, simulation, control chart.

\section{Introdução}

A simulação é uma ferramenta que possibilita estimar o comportamento de um modelo de sistema discreto, contínuo ou misto de operação, por meio da sua modelagem lógico-matemática. Sua principal vantagem é poder manipular condições de operações das entidades modeladas quando, na prática, seriam muito difíceis de serem realizadas, devido às limitações de naturezas diversas.

Estudou-se a moagem seletiva de mesclas binárias, observando-se a evolução granulométrica dos produtos a partir das características de alimentação de cada componente, de suas proporções e do tempo de processamento. 
Diferentemente da maioria dos trabalhos de simulação de moagem encontrados na literatura, o presente trabalho não utiliza o modelo de balanço populacional tradicional. Alternativamente, o presente artigo abrange uma

Onde $Y_{i}$ é a fração passante acumulada do material na fração granulométrica $i[-] ; x_{i}$ é o diâmetro médio do intervalo $i[\mu \mathrm{m}] ; a$ é o coeficiente de agudez da distribuição [-]; $d_{50}$ é o diâmetro médio

\section{Revisão da literatura}

A simulação probabilística originou-se de uma extensão do método de Monte Carlo, elaborado e proposto por von Neumann e Ulam, durante a Segunda Guerra Mundial, para solução de problemas matemáticos de difícil tratamento analítico (Saliby, 1989).

A simulação é realizada tendo como objeto um modelo. Um modelo é a representação do sistema de interesse que se presta ao estudo de possíveis melhorias no sistema real ou à análise do

\section{Modelo de balanço populacional}

No processo de cominuição, partículas alimentadas tornam-se mais finas por efeito do meio moedor e das partículas grosseiras e daquelas geradas (partículas filhas) em função de sucessivos eventos de quebra. Partindo-se de princípio básico, a distribuição de tamanhos dos produtos não pode ser descrita diretamente por meio dos parâmetros de entrada (Herbst \& Fuerstenau, 1980), o

Onde $m_{i}(t)$ representa a fração em massa das partículas no intervalo de tamanho $i$ no tempo $t ; k_{i}(t)$ representa a função de taxa de que-

\section{Redes Neurais Artificiais (RNAs)}

As RNAs representam uma abordagem em inteligência artificial (IA), sendo utilizadas para implementar inteligência em máquinas (computadores digitais) e são embasadas em modelos que emulam a estrutura de funcionamento dos neurônios no cérebro humano (Luger, 2004). Sua origem remonta aos modelos proposta de aplicação de redes neurais artificiais (RNA) ao estudo da cominuição mista.

Para tanto, as distribuições granulométricas foram descritas, simplificadamente, em termos de diâmetro media-

$$
Y_{i}=\frac{x_{i}^{\mathrm{a}}}{x_{i}^{\mathrm{a}}+d_{50}^{\mathrm{a}}}
$$

da distribuição $[\mu \mathrm{m}]$.

Os resultados experimentais serviram para treinar e testar um simulador de moagem mista baseado em RNA. O objetivo buscado

impacto de mudanças em estratégias operacionais (Pidd, 1998). Normalmente modelos são representações simplificadas do mundo real, que mantêm, para determinadas situações e enfoques, graus aceitáveis de equivalência (Goldbarg, 2000).

De acordo com Bôas (1993), os trabalhos de modelagem e simulação de circuitos minerometalúrgicos tiveram seu início de desenvolvimento na Austrália, pela Mount Isa, dando origem ao $J K$

que confere ao método de modelagem de moagem caráter fenomenológico (Fuerstenau et al., 2010).

Tratando-se do estudo de moagem em batelada, entra em cena o chamado modelo de balanço populacional (também chamado de modelo de tempo contínuo e tamanho discreto), no qual as partículas são classificadas em faixas de tamanhos numeradas de 1 a $n$, sendo que

$$
\left[d m_{i}(t) / d t\right]=-k_{i}(t) m_{i}(t)+\sum b_{i j} k_{j}(t) m_{j}(t)
$$

bra (também chamada função de seleção) relacionada ao tamanho $i$; $b_{i j}$ representa a função distribuição de quebra definida como a fração de

matemáticos e de engenharia de neurônios biológicos (Kovács, 2006).

A concepção de RNA ocorreu na década de 40 pelo neurofisiologista Warren McCulloch e pelo matemático Walter Pitts, que estabeleceram analogia entre as células nervosas vivas e o processamento eletrônico (Tafner et al., 1996). no e agudez da distribuição sigmoidal de Hill (praticamente equivalente à de Rosin-Rammler no sistema em estudo, com coeficiente de correlação mínimo de 97\%), conforme a Equação 1, mostrada a seguir:

foi - além de testar uma nova aplicação para RNA - tentar simplificar e otimizar o estudo da moagem, processo largamente utilizado na indústria.

Mineral Research Centre, por volta de 1960. A partir disso, a simulação vem sendo estudada e aplicada na indústria mineral em todo o mundo.

Alves et al.(2004) ressaltam que a simulação de cominuição fundamentada nos modelos de balanço populacional têm obtido grande êxito em diversos projetos de aplicação, fornecendo condições satisfatórias de simulação do circuito, gerando ganhos em vários aspectos do controle industrial.

o balanço de massa é realizado através da observação da evolução granulométrica em tais faixas em função do tempo (Fuerstenau et al., 2010).

Matematicamente pode-se expressar, para qualquer intervalo de tamanho $i$, em função do tempo $d t$, a seguinte equação cinética (Fuerstenau et al., 2004; Fuerstenau et al., 2010):

partículas filhas, de tamanho $i$, originadas de quebras da fração de partículas do tamanho $j$ (com $j$ maior ou igual a $i$ ).

A partir da década de 80 , surgiram inúmeros modelos para desenvolver e aplicar essa técnica, motivados pelos avanços metodológicos e pela disponibilidade de recursos computacionais (Ferneda, 2006).

De acordo com Medeiros (1999), para que as soluções derivadas do uso de 
RNA tenham desempenho satisfatório, os problemas devem ser tolerantes a uma determinada imprecisão, dispor de uma grande quantidade de dados de treinamento e não necessitar de regras de decisão discretas. Algumas aplicações clássicas das RNAs são: o reconhecimento de padrões em imagens, processamento de voz, processamento de sinais, análise de séries temporais, simulação de sistemas biológicos, diagnósticos médicos e previ-

\section{O perceptron}

A Figura 1 apresenta um modelo de neurônio denominado perceptron, pesquisado e desenvolvido por Rosenblatt nas décadas de 50 e 60 .

Nesse modelo de neurônio, as variáveis apresentadas são as seguintes: $x_{i}$ é a entrada do neurônio i; $w_{i}$ é o peso das

Figura 1

Modelo de um neurônio perceptron de Rosenblatt.

Fonte: Adaptado de Medeiros (2006, p. 3).

Para se obter o valor da saída intermediária $s$, realiza-se o somató-

A função denominada função de ativação ou de transferência modula a amplitude do intervalo do sinal de saída do neurônio para algum valor finito, nor-

Onde $\rho$ é a constante de translação da curva $y_{i}$ e $\lambda$ é a constante de inclinação da curva $y_{i}$.

Uma característica muito importante das RNAs é a capacidade de aprender por meio de treinamento e, com isso, melhorar seu desempenho, em termos de reprodução de uma saída desejada, partindo-se de um conjunto de entrada. A aprendizagem se completa quando a RNA chega a uma solução generalizada para uma classe de problemas. sões no mercado financeiro.

Uma RNA, similarmente ao seu paralelo biológico, é composta por determinado número de neurônios conectados por conexões sinápticas. Cada sinapse possui um peso associado, onde o conhecimento acumulado na rede depende, diretamente, da atualização desses pesos. Alguns desses neurônios são conectados ao ambiente externo, tratando-se das entradas e das

sinapse i; $w_{o}$ é o viés ou bias; $s$ é a saída intermediária; $\boldsymbol{o}$ é a saída ativada.

Através das entradas $x_{i}$, são apresentados os valores que se desejam processar. Os pesos das sinapses $w_{i}$ (que representam o aprendizado da rede) assumirão valores que, aplicados aos valo-

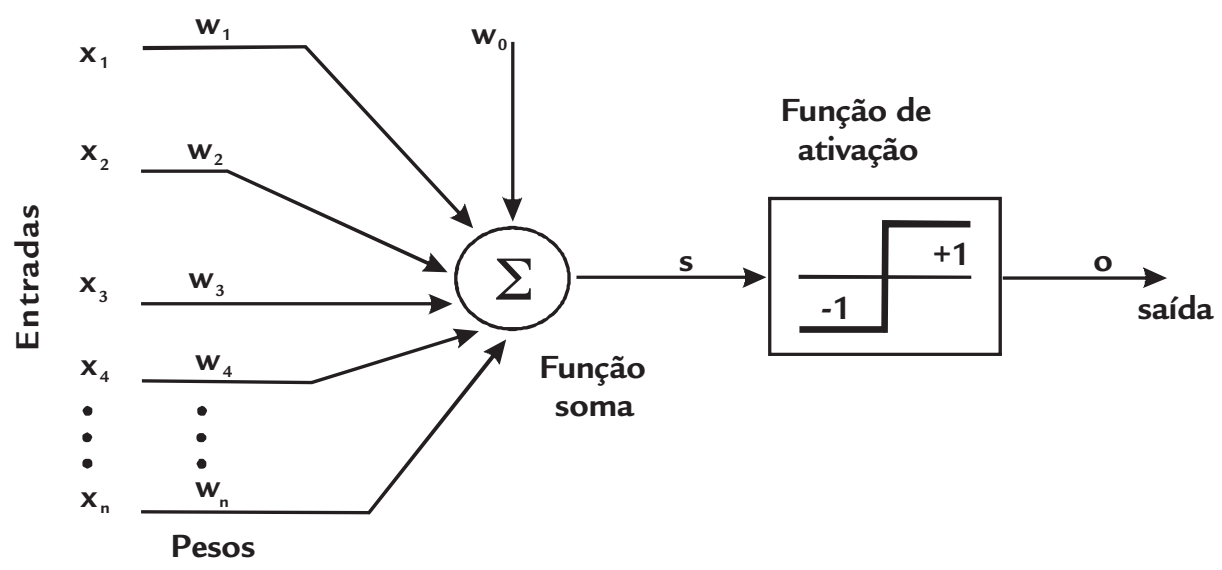

rio da multiplicação entre as entradas e seus respectivos pesos numa função

$$
s=\sum\left(x_{j} w_{i j}\right)+w_{o}
$$

malmente no intervalo $[-1,1]$ ou $[0,1]$.

Das funções de ativação utilizáveis, a de uso mais comum é a sigmoidal, por apresentar algumas características

$$
y_{i}=\frac{1}{1+e^{\left(-\lambda s_{i}+\rho\right)}}
$$

De acordo com Tafner et al. (1996), os principais modelos de aprendizagem são:

- Aprendizagem supervisionada - Nesse modelo de aprendizagem a rede neural é treinada com ajuda de um professor ou treinador, isto é, apresentam-se pares de entrada à rede, cujas saídas são comparadas às saídas desejadas. Os ajustes nos pesos das conexões sinápticas são realizados de acordo com as diferenças entre as saídas obtidas e as respectivas saídas saídas da rede. Cada neurônio possui um conjunto de entradas e de saídas ligadas a outros neurônios, exceto os neurônios de entrada e de saída que possuem um ou outro. Um neurônio possui um patamar de ativação que deriva da conjugação das entradas atuais recebidas com os pesos sinápticos das conexões, cujo valor resultante poderá ativar ou não as saídas desse neurônio (Medeiros, 2006).

res de entrada, resultarão numa saída intermediária $s$. Tais pesos são atualizados por meio de um processo de treinamento prévio. A variável $w_{o}$, denominada viés (bias), não multiplica nenhuma entrada, possui valor fixo e funciona como uma espécie de ajuste fino (Medeiros, 2006).

denominada soma, ou seja:

vantajosas, tais como: continuidade, monotonicidade, não linearidade e diferenciabilidade em qualquer ponto. Sua expressão é:

desejadas, obtendo-se, dessa maneira, o armazenamento de conhecimento. A iteratividade de treino deve ser repetida com todo o conjunto de treinamento até que a taxa de erro atinja uma determinada faixa que seja considerada satisfatória. Esse modelo de aprendizagem é amplamente conhecido e tem obtido excelentes resultados em aplicações reais.

- Aprendizagem não supervisionada - Nesse modelo de aprendizagem, 
também conhecido como auto-supervisionado, não se utilizam saídas desejadas, ou seja, para treinamento da rede são disponibilizados apenas conjuntos de entrada. A rede processa as entradas e se organiza classificando-as a partir de critérios próprios.

\section{Algoritmo de retropropagação}

A rede neural do tipo retropropagação consiste numa rede neural tipo feedforward treinada com o algoritmo de retropropagação. Motivada pela grande popularidade desse método, para o treinamento de RNA, as redes treinadas, por meio desse método, são denominadas redes de retropropagação.

De acordo com Paula (2007), a grande vantagem da utilização do método de retropropagação reside no fato de existirem uma quantidade de equações bem definidas e explícitas voltadas para a correção dos pesos na rede. A correção do erro, nos pesos das sinapses, é realizada por meio da retropropagação do erro obtido na comparação entre a

\section{Materiais e métodos}

O sistema baseado em RNA foi construído a partir de uma componente MLP desenvolvida por Medeiros (2006) para o ambiente Delphi $7^{\circledR}$, que depende da unit denominada MLP.pas, a qual contém as funções e os métodos básicos necessários à implementação de uma RNA perceptron multicamada com momento (disponível em: http://www.visualbooks.com.br/shop/ Downloads.asp).

A análise topológica indicou que a configuração constituída por uma camada neuronal de entrada, duas camadas intermediárias e uma camada de saída mostrou-se adequada para a aplicação requerida, adotando-se o número de corridas igual a 1000.

Os dados experimentais utilizados provieram de trabalho anterior (Rosa \& Luz, 2010). A RNA foi alimentada apenas com as informações: percentual do mineral dolomita, percentual do
A auto-organização observada, em redes neurais desenvolvidas com este tipo de aprendizado, envolve processo de competição e de cooperação entre neurônios.

O denominado perceptron multicamadas consiste numa generalização do

saída gerada pela rede e a resposta desejada, objetivando-se, assim, diminuir o erro total da saída gerada pela rede.

Considerando uma rede com retropropagação, o ajuste do erro é feito pela retropropagação do erro, realizando-se, para isso, uma distribuição do erro referente aos neurônios de saída para os demais neurônios da rede. Contudo, apesar de ser possível conhecer o erro global, não há meio de se determinarem, com exatidão, os pesos para corrigi-los. Com base no erro global, entretanto, é possível determinar as direções nas quais os pesos precisam ser ajustados no sentido de minimizar o erro quadrático total na saída da rede. perceptron de camada única.

Segundo Rossomando (2006), a capacidade que as RNAs possuem de aproximar funções com grau arbitrário de precisão provavelmente justifica sua ampla aplicabilidade no campo da identificação e controle de processos.

De posse dessas direções, torna-se possível ajustar os pesos, buscando-se atingir o menor erro global.

Segundo Loesch e Sari (1996), visando a acelerar o treinamento da rede neural, pode ser utilizada o que se chama de técnica dos momentos, a qual consta da inclusão de um termo proporcional à atualização dos pesos da interação imediatamente anterior ao cálculo da atualização de pesos atual. Tal termo caracteriza-se como uma constante denominada momentum ou momento, que permite uma associação convexa entre a contribuição do gradiente com a variação prévia nos pesos sinápticos. mineral quartzo, diâmetro mediano da alimentação (diâmetro $d_{50}$ ), coeficiente de agudez da alimentação e tempo de moagem, nessa ordem. $\mathrm{Na}$ camada de saída, obtiveram-se: diâmetro mediano da dolomita, coeficiente de agudez da dolomita, diâmetro mediano do quartzo e coeficiente de agudez do quartzo, nessa ordem.

Foram utilizados conjuntos distintos de dados para treinar e testar a RNA, como mostra a Tabela 1.

Para avaliar, estatisticamente, os resultados, utilizou-se o indice qualitativo de simulação (IQS), obtido em cada conjunto de corridas de simulação como característica da qualidade para avaliar as saídas do simulador. O IQS corresponde à multiplicação do somatório dos módulos dos erros totais dos parâmetros simulados: fator de agudez e diâmetro $d_{50}$.

Realizaram-se 30 simulações con- secutivas, obedecendo aos parâmetros de simulação definidos, a fim de se obterem dados para testar, estatisticamente, o desempenho do processo de simulação.

Nesse sentido, foi possivel avaliar a estabilidade estatística do processo de simulação por meio de uma ferramenta da qualidade denominada carta de controle, que determina, por meio do sistema $3 \sigma$, limites máximos dentro dos quais os valores gerados pelo processo podem oscilar, de forma aleatória, em torno de uma linha central, que representa a média para esses valores.

Essa ferramenta estatística pode ser utilizada, se alguns requisitos forem observados. Esses requisitos exigem que se tenha um conjunto de amostras superior a 20 e que a distribuição de probabilidades dos valores das amostras siga o padrão da distribuição normal (Montgomery, 2001).

\section{Resultados e discussão}

A Tabela 2 dispõe os resultados das 30 simulações consecutivas configuradas com duas camadas ocultas, com 5 neurônios em cada camada e com 1000 corridas, explicitando-se o IQS.

Conforme mostra a Figura 2, houve aderência satisfatória dos valores de IQS ao padrão normal, pois o p-value superou o valor do nível de significância adotado, implicando a aceitação da hipótese nula, ou seja, a distribuição dos valores segue o padrão da distribuição normal.
O pacote estatístico MiniTab®, versão 15 , foi utilizado para se realizar o teste.

Devido às características dos dados, a utilização da carta de controle Shewhart, para medidas individuais, mostrou-se eficaz. A carta de Shewhart, 
Tabela 1

Conjuntos de dados utilizados como padrões de treinamento e de teste da RNA.

\begin{tabular}{|c|c|c|c|c|c|c|c|}
\hline \multirow{2}{*}{$\begin{array}{l}\text { Amostra } \\
\text { (Padrão) }\end{array}$} & \multirow{2}{*}{$\begin{array}{c}\text { Proporção } \\
\text { dolomita: } \\
\text { quartzo }\end{array}$} & \multirow{2}{*}{$\begin{array}{c}\text { Tempo de } \\
\text { moagem } \\
\text { (minutos) }\end{array}$} & \multicolumn{2}{|c|}{$a[-]$} & \multicolumn{2}{|c|}{$d_{s o}[\mu \mathrm{m}]$} & \multirow{2}{*}{$\begin{array}{c}\text { Classificação } \\
\text { dos dados }\end{array}$} \\
\hline & & & Dolomita & Quartzo & Dolomita & Quartzo & \\
\hline $\mathrm{T} 25 \mathrm{D} / 75 \mathrm{Q}$ & $25 \%: 75 \%$ & 5 & 1,0219 & 1,7361 & 397 & 1010 & Treinamento \\
\hline $\mathrm{T} 25 \mathrm{D} / 75 \mathrm{Q}$ & $25 \%: 75 \%$ & 15 & 1,5523 & 1,7659 & 174 & 808 & Treinamento \\
\hline $\mathrm{T} 25 \mathrm{D} / 75 \mathrm{Q}$ & $25 \%: 75 \%$ & 30 & 2,1026 & 1,8611 & 154 & 507 & Treinamento \\
\hline $\mathrm{T} 25 \mathrm{D} / 75 \mathrm{Q}$ & $25 \%: 75 \%$ & 50 & 2,5578 & 2,0406 & 142 & 397 & Treinamento \\
\hline $\mathrm{T} 25 \mathrm{D} / 75 \mathrm{Q}$ & $25 \%: 75 \%$ & 75 & 3,2852 & 2,4255 & 158 & 330 & Treinamento \\
\hline T50D/50Q & $50 \%: 50 \%$ & 5 & 1,0725 & 1,7461 & 382 & 1070 & Treinamento \\
\hline T50D/50Q & $50 \%: 50 \%$ & 15 & 1,447 & 1,8145 & 200 & 860 & Treinamento \\
\hline T50D/50Q & $50 \%: 50 \%$ & 30 & 2,2179 & 1,8646 & 138 & 625 & Treinamento \\
\hline T50D/50Q & $50 \%: 50 \%$ & 50 & 2,2567 & 1,8101 & 114 & 449 & Treinamento \\
\hline T50D/50Q & $50 \%: 50 \%$ & 75 & 3,1389 & 2,2308 & 145 & 355 & Treinamento \\
\hline T75D/25Q & $75 \%: 25 \%$ & 5 & 1,0689 & 1,7913 & 364 & 1170 & Treinamento \\
\hline $\mathrm{T75D} / 25 \mathrm{Q}$ & $75 \%: 25 \%$ & 15 & 1,3862 & 1,7775 & 195 & 829 & Treinamento \\
\hline T75D/25Q & $75 \%: 25 \%$ & 30 & 2,0301 & 1,877 & 140 & 625 & Treinamento \\
\hline T75D/25Q & $75 \%: 25 \%$ & 50 & 2,4957 & 1,8219 & 124 & 417 & Treinamento \\
\hline T75D/25Q & $75 \%: 25 \%$ & 75 & 2,843 & 2,1324 & 111 & 373 & Treinamento \\
\hline $\mathrm{T} 25 \mathrm{D} / 75 \mathrm{Q}$ & $25 \%: 75 \%$ & 22 & 1,8064 & 1,8064 & 156 & 668 & Teste \\
\hline T50D/50Q & $50 \%: 50 \%$ & 23 & 1,8423 & 1,8423 & 170 & 739 & Teste \\
\hline T75D/25Q & $75 \%: 25 \%$ & 25 & 1,8459 & 1,8459 & 157 & 681 & Teste \\
\hline
\end{tabular}

\begin{tabular}{|c|c|c|c|}
\hline \multirow{2}{*}{ Simulação } & \multicolumn{2}{|c|}{ Erro Total } & \multirow{2}{*}{$\mathrm{IQS}[\mu \mathrm{m}]$} \\
\hline & $a[-]$ & $D_{50}[\mu \mathrm{m}]$ & \\
\hline 1 & 0,4142 & 328,96 & 136 \\
\hline 2 & 0,3276 & 51,03 & 17 \\
\hline 3 & 0,205 & 209,62 & 43 \\
\hline 4 & 0,5722 & 439,73 & 252 \\
\hline 5 & 0,6902 & 615,38 & 425 \\
\hline 6 & 0,5396 & 328,72 & 177 \\
\hline 7 & 0,3784 & 338,32 & 128 \\
\hline 8 & 0,5015 & 159,86 & 80 \\
\hline 9 & 0,4295 & 393,52 & 169 \\
\hline 10 & 0,4379 & 357,41 & 157 \\
\hline 11 & 0,3128 & 143,78 & 45 \\
\hline 12 & 0,5672 & 259,48 & 147 \\
\hline 13 & 0,5024 & 278,92 & 140 \\
\hline 14 & 0,6502 & 467,98 & 304 \\
\hline 15 & 0,396 & 312,74 & 124 \\
\hline 16 & 0,3865 & 229,42 & 89 \\
\hline 17 & 0,249 & 132,70 & 33 \\
\hline 18 & 0,3909 & 175,54 & 69 \\
\hline 19 & 0,2648 & 150,86 & 40 \\
\hline 20 & 0,5921 & 284,12 & 168 \\
\hline 21 & 0,2689 & 257,97 & 69 \\
\hline 22 & 0,1928 & 243,53 & 47 \\
\hline 23 & 0,1494 & 177,00 & 26 \\
\hline 24 & 0,5418 & 284,44 & 154 \\
\hline 25 & 0,3693 & 344,65 & 127 \\
\hline 26 & 0,8241 & 544,81 & 449 \\
\hline 27 & 0,4795 & 379,41 & 182 \\
\hline 28 & 0,3499 & 157,21 & 55 \\
\hline 29 & 0,3208 & 167,99 & 54 \\
\hline 30 & 0,5237 & 410,38 & 215 \\
\hline Média & 0,42761 & 287,516 & 137 \\
\hline
\end{tabular}

para valores individuais preliminares, é apresentada na Figura 3 e indica que a simulação se apresenta sob controle estatístico em termos de dispersão dos valores de IQS; o mesmo, porém, não ocorreu para a avaliação da locação da média dos valores individuais.

Como apenas dois pontos extrapolaram os limites de controle, como medida usual, coube desconsiderá- los, caracterizando-os como exceções do processo de simulação. $\mathrm{Na}$ carta de controle recalculada, não se percebem pontos fora dos limites, nem tampouco indícios de falta de alea- 
toriedade na distribuição dos pontos em torno da linha central, indicando que o processo de simulação está sob controle estatístico, o que lhe confere previsibilidade. Após exclusão dos dados das simulações de números 5 e
26, os limites foram recalculados com o restante das amostras, como mostra a Figura 4.

\section{Teste gráfico de aderência à curva de distribuição normal}

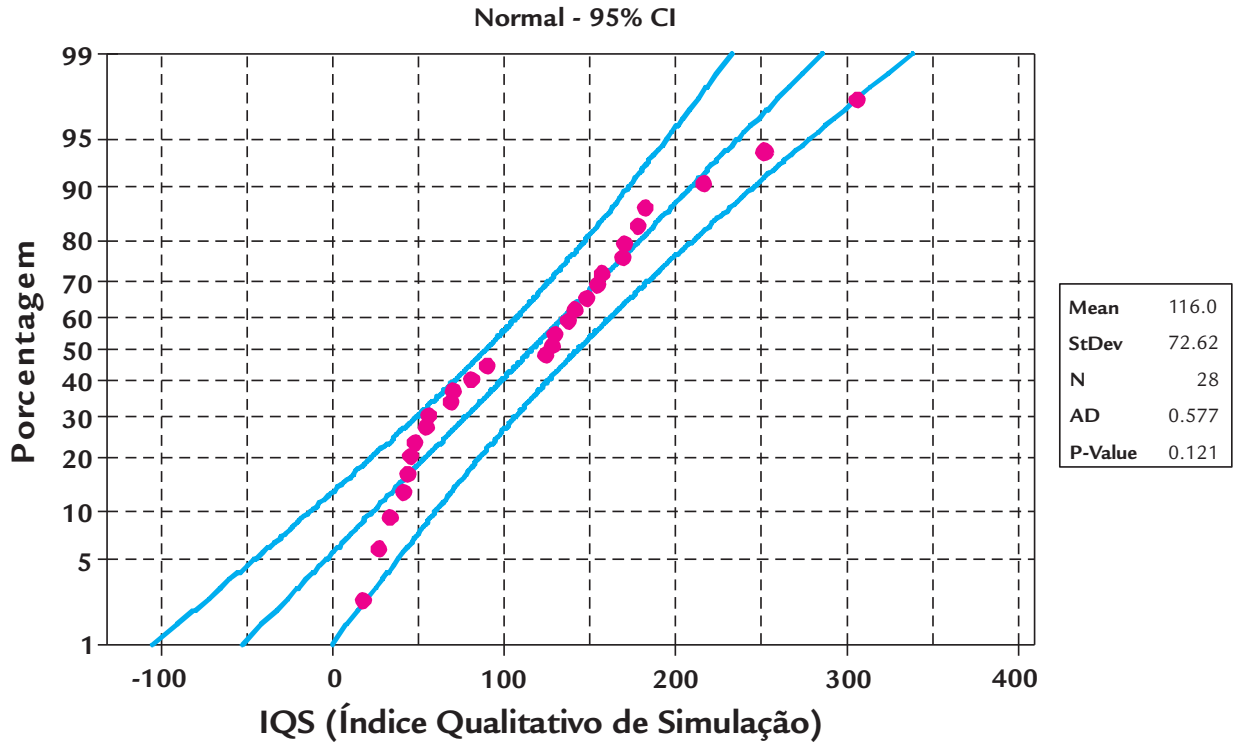

Figura 2

Teste de aderência realizado para os valores do IQS com relação ao padrão de distribuição normal.
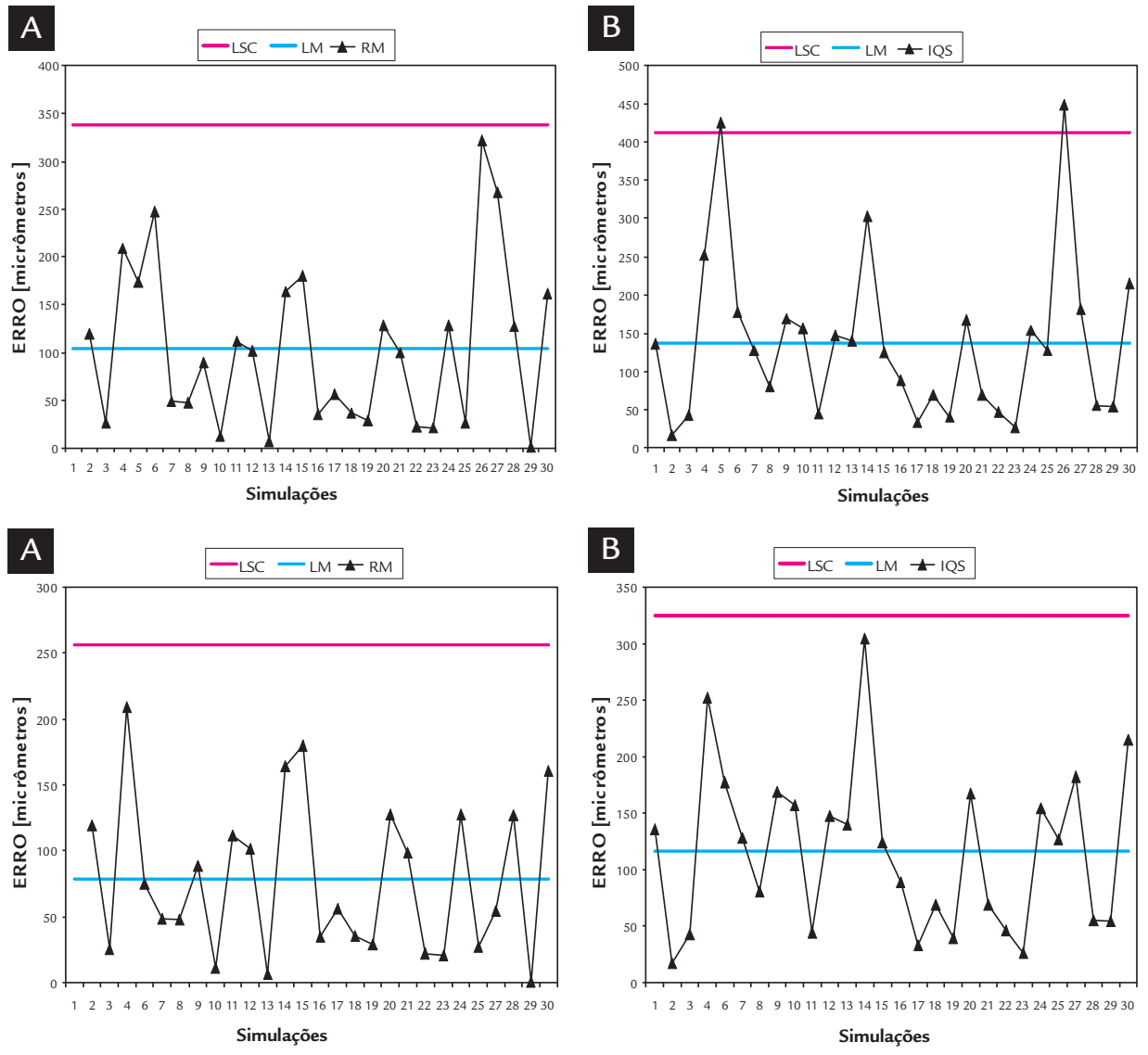

As Figuras 5 e 6 ilustram as distribuições granulométricas simuladas de menor valor de IQS (simulação de número 2) e maior valor de IQS (simulação de número 14), respectivamente, para cada padrão de mescla com as respectivas curvas determinadas. A fração retida simples é plotada em função do diâmetro médio da classe granulométrica (média

aritmética de peneiras contíguas da série ANBT/Tyler). Há proximidade satisfatória, com contrastes máximos da ordem de menos de $7 \%$, exceto para o padrão T25D/75Q, que apresentou contraste máximo da ordem de $19 \%$, na simulação de maior IQS.

A Figura 7 mostra o comportamento do IGCG, nas simulações de maior e
Figura 3

Carta de Shewhart preliminar:

A) Amplitudes móveis.

B) Valores individuais.
Figura 4

Carta de Shewhart com expurgo:

A) Amplitudes móveis.

B) Valores individuais.

de menor IQS. Segundo o gráfico, as discrepâncias, em termos de IGCG, ocorreram no padrão T25D/75Q-22, segundo a simulação de maior IQS.

Como forma de se sistematizar a aceitação das atualizações das sinapses na fase de treinamento, pode-se utilizar os limites determinados nos gráficos de controle. 

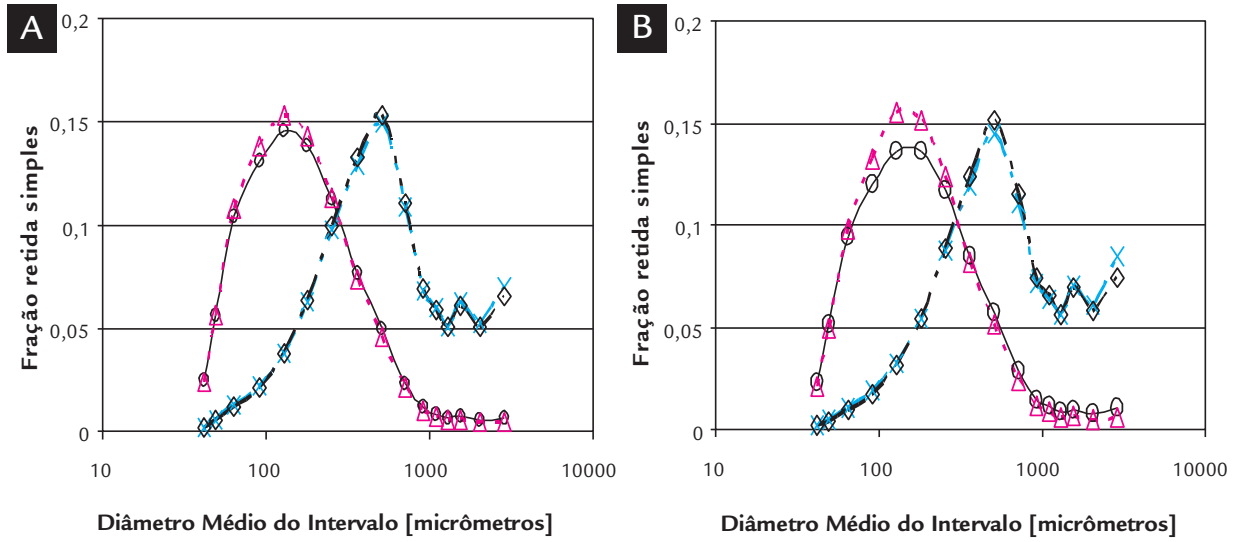

Figura 5

Curvas granulométricas simuladas (com menor IQS) e determinadas para os minerais no produto das moagens das mesclas

A) T25D/75Q-22.

B) $\mathrm{T} 50 \mathrm{D} / 50 \mathrm{Q}-23$.

C) $T 75 \mathrm{D} / 25 \mathrm{Q}-25$.
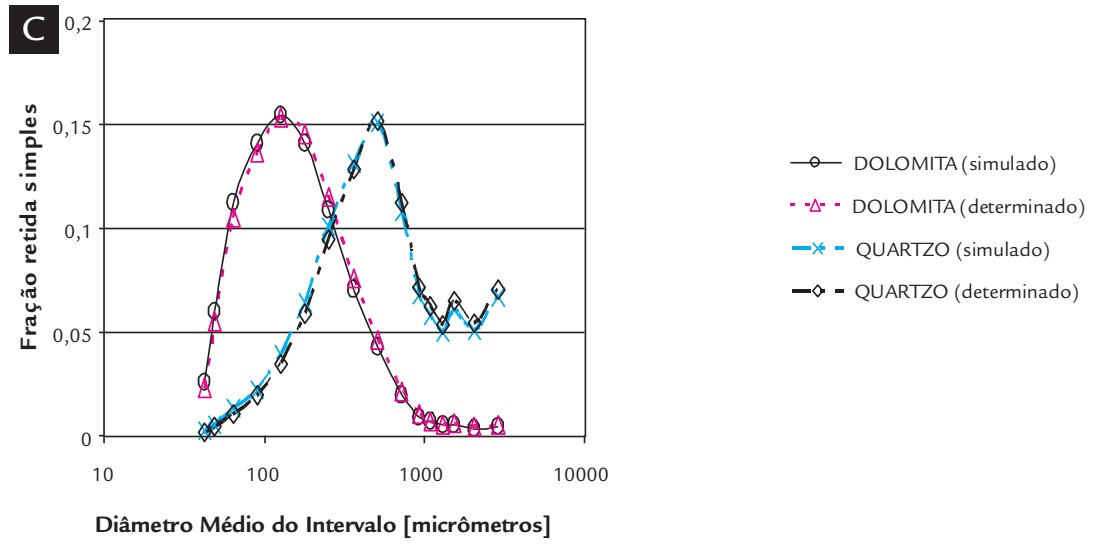

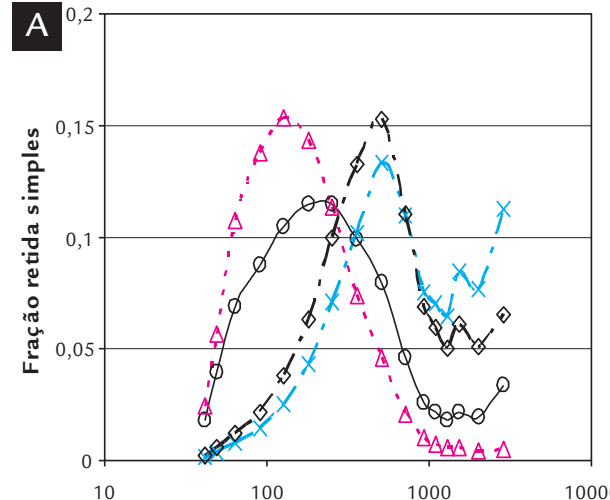

Diâmetro Médio do Intervalo [micrômetros]

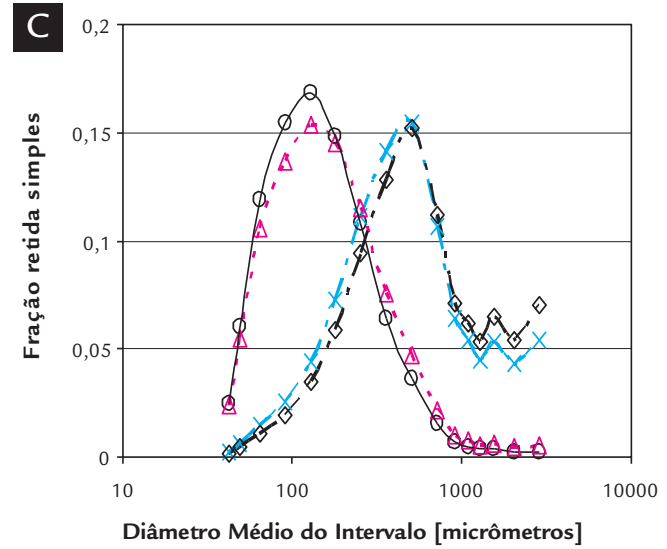

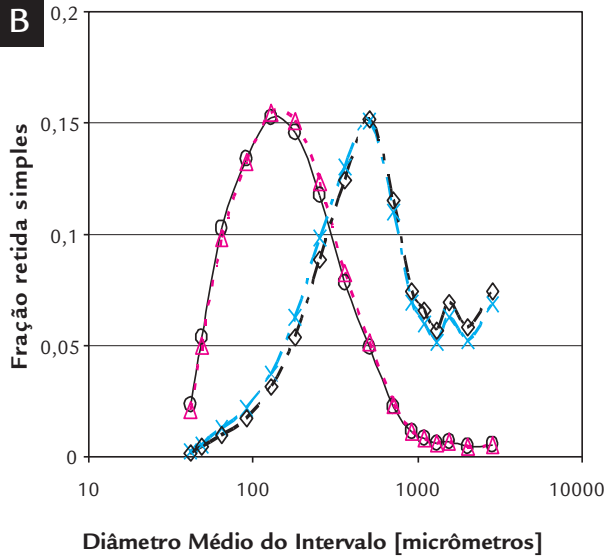

- DOLOMITA (simulado)

- - - - DOLOMITA (determinado)

-*- QUARTZO (simulado)

- - QUARTZO (determinado)

as granulométricas simuladas (com maior IQS) e determinadas para os minerais no produto das moagens das mesclas

A) T25D/75Q-22.

B) $T 50 \mathrm{D} / 50 \mathrm{Q}-23$.

C) $\mathrm{T} 75 \mathrm{D} / 25 \mathrm{Q}-25$.

\section{Conclusão}

O simulador de moagem mista baseado em RNA perceptron multicamada com momento se mostrou eficaz na maioria das simulações realizadas, apesar da escassez de dados de treinamento e de teste. A utilização de carta de controle
Shewhart, para valores individuais, permitiu avaliar a estabilidade estatística do processo de simulação em relação à dispersão 


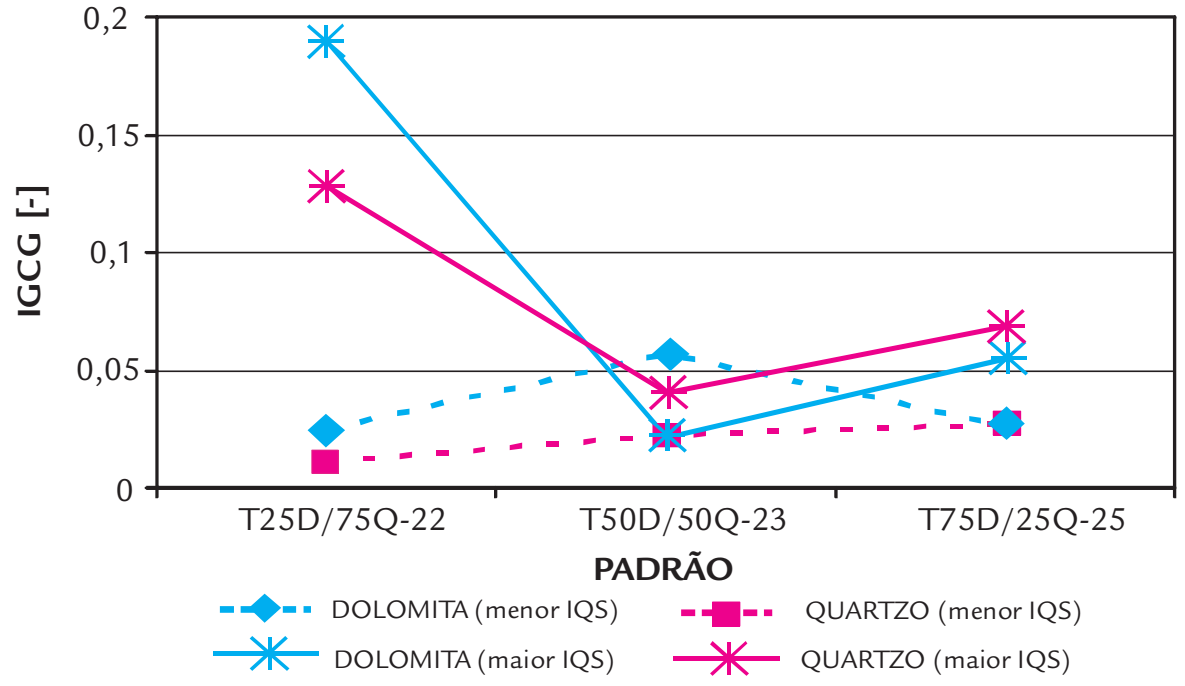

dos valores e à locação da média dos erros, além de propiciar manipulação segura dos dados, sistematizando, de forma mais eficiente, a aceitação das atualizações de pesos geradas na fase de treinamento.

\section{Referências bibliográficas}

Figura 7

Comportamento do IGCG

nas simulações de maior e menor IQS.

Portanto uma nova aplicação para RNA foi testada como boas perspectivas futuras de trabalhos de aperfeiçoamento nessa área, tanto em termos de algoritmo, quanto em termos de metodologia.

ALVES, V. K. et al. Estudo de otimização de carga de moinho utilizando tecnologia de simulação. In: MENEZES. C. T. B. de et al. (Ed.). ENCONTRO NACIONAL DE TRATAMENTO DE MINÉRIOS E METALURGIA EXTRATIVA, 20. Florianópolis: Unesc: 2004. v. 2, p. 227-234.

BÔAS, R. C. V. Apresentação. In: CARRISSO, R. C. C., POSSA, M. V. Simulação de moagem de talco utilizando seixos. Rio de Janeiro: CETEM/CNPq, 1993. 24 p.

FERNEDA, E. Redes neurais e sua aplicação em sistemas de recuperação de informação. Ci. Inf., Brasília, v. 35, n. 1, Apr. 2006. Available from <http://www. scielo.br.ez27.periodicos.capes.gov.br/scielo.php?script=sci_arttext\&pid=S0100 19652006000100003\&lng=en\&nrm=iso>. Access on 29 Sept. 2011.

FUERSTENAU, D. W. et al. Linear and nonlinear particle breakage processes in comminution systems. Intenational Jornal of Mineral Processing, 74S (2004) S317-S327.

FUERSTENAU, D. et al. Effect of particulate environment on the kinetics and energetics of dry ball milling. International Journal of Mineral Processing, v. 97, p. 52-58, 2010.

GOLDBARG, M. C. Otimização combinatória e programação linear: modelos e algoritmos. Rio de Janeiro: Campus, 2000. 649 p.

HERBST, J.A., FUERSTENAU, D. W. Scale-up procedure for continuous grinding mill design using PBM. International Journal of Mineral Processing, v. 7, p. 1-31, 1980.

KOVÁCS, Z. L. Redes neurais artificiais: fundamentos e aplicações: um texto básico. (4. Ed.). São Paulo: Livraria da Física, 2006. 174 p.

LOESCH, C., SARI, S. T. Redes neurais artificiais: fundamentos e modelos. Blumenau: Ed. da FURB, 1996. 166 p.

LUGER, G. F. Inteligência artificial: estruturas e estratégias para a resolução de problemas complexos. (4. Ed.). Porto Alegre: Bookmann, 2004. 774 p.

MEDEIROS, J. S. de. Banco de dados geográficos e redes neurais artificiais: tecnologias de apoio à gestão do território. São Paulo: Universidade de São Paulo, 1999. 221 p. (Tese de Doutorado).

MEDEIROS, L. F. de. Redes neurais em Delphi. (2. Ed.). Florianópolis: Visual Books, 2006. $210 \mathrm{p}$.

MONTGOMERY, D. C. Introdução ao controle estatístico da qualidade. (4. Ed.). Rio de Janeiro: LCT, 2001. 513 p.

PAULA, W. C. F. de. Análise de superfície de peças retificadas com o uso de redes neurais artificiais. Bauru: Universidade Estadual Paulista, 2007. 151 p. (Dissertação de Mestrado). 
PIDD, M. Computer simulation in management science (4. Ed.). Chichester: John Wiley \& Sons, 1998. 311 p.

ROSA, G. M., LUZ, J. A. M. da. Seletividade na cominuição de mesclas de dolomita e quartzo. REM - Revista Escola de Minas, v. 63, n. 4, p. 679-684, Dez. 2010.

ROSSOMANDO, F. G. Estabelecimento de estratégias de controle inteligente na laminação de produtos planos. Vitória: Universidade Federal do Espírito Santo, 2006. $164 \mathrm{p}$.

SALIBY, E. Repensando a simulação: a amostragem descritiva. São Paulo: Atlas/ EDUUFRJ, 1989. $182 \mathrm{p}$.

TAFNER, M. A. et al. Redes neurais artificiais: introdução e princípios de neurocomputação. Blumenau: Ed. da FURB, 1996. 199 p.

Artigo recebido em 06 de janeiro de 2010. Aprovado em 21 de novembro de 2011. 